\title{
Physicomechanical, Optical, Barrier, and Wide Angle X-ray Scattering Studies of Filled Low Density Polyethylene Films
}

\author{
Siddaramaiah, ${ }_{3}^{1}$ K. H. Guruprasad, ${ }^{1}$ R. T. Nagaralli, ${ }^{2}$ H. Somashekarappa, ${ }^{3}$ T. N. Guru Row, ${ }^{4}$ \\ R. Somashekar ${ }^{3}$ \\ ${ }^{1}$ Department of Polymer Science and Technology, Sri Jayachamarajendra College of Engineering, Mysore-570 006, India \\ ${ }^{2}$ Central Institute of Plastics Engineering and Technology, Mysore-570 016, India \\ ${ }^{3}$ Department of Studies in Physics, University of Mysore, Mysore-570 006, India \\ ${ }^{4}$ Solid State Structural Chemical Unit, Indian Institute of Sciences, Bangalore-560 012, India
}

Received 8 February 2005; accepted 22 July 2005

DOI 10.1002/app.23504

Published online 9 February 2006 in Wiley InterScience (www.interscience.wiley.com).

\begin{abstract}
Series of low density polyethylene (LDPE) films filled with different fillers such as silica, mica, soya protein isolate, potassium permanganate, and alumina were processed using a single screw extruder. The filled LDPE films were characterized for physicomechanical properties like tensile strength, percentage elongation at break, and tear strength, optical properties like percent transmission and haze. The barrier properties such as water vapor transmission rate and oxygen transmission rate of the filled LDPE
\end{abstract}

films have also been reported. Microcrystalline parameters such as crystal size $(\langle N\rangle)$ and lattice distortion $(g)$ of the filled LDPE films obtained using wide angle X-Ray scattering method have been reported. (c) 2006 Wiley Periodicals, Inc. J Appl Polym Sci 100: 2781-2789, 2006

Key words: polyethylene; fillers; mechanical properties; barrier; wide angle $\mathrm{X}$-ray scattering

\section{INTRODUCTION}

Plastics packaging has aroused enormous interest in the field of packaging technology for the advantages they offer over traditional packaging materials like wood, paper, metal, etc. The thermoplastics especially owing to their superior properties have been posing a strong challenge to the conventional packaging materials. This has paved the way for the research works leading toward the improvement of these thermoplastic materials in terms of physicomechanical, barrier, and other properties by incorporating various fillers/ blends/copolymers to make them suitable for different application areas. Several works have been reported, wherein different fillers like mica, silica, calcium carbonate, titanium oxide, and alumina have been incorporated and their effects on physical properties have been extensively quantified. Earlier investigators have studied films of low density polyethylene (LDPE) and its modified films to find their applicability to store food products (increasing the shelf life) and also for biodegradable aspects. ${ }^{1-19}$

However, the effect of fillers such as mica, silica, soya protein isolate, potassium permanganate $\left(\mathrm{KMnO}_{4}\right)$, and

Correspondence to: Siddaramaiah (poly@sjce.ac.in).

Journal of Applied Polymer Science, Vol. 100, 2781-2789 (2006) (C) 2006 Wiley Periodicals, Inc. alumina $\left(\mathrm{Al}_{2} \mathrm{O}_{3}\right)$ in LDPE films on microstructural changes and hence on the physical properties have not been addressed so far. Some of the physicomechanical and optical properties of filled LDPE and LLDPE films have been published in our earlier publication. ${ }^{19}$ In continuation, we report here the physicomechanical, optical and barrier properties, and microstructural parameters by wide angle X-ray scattering studies of the filled LDPE films.

\section{EXPERIMENTAL}

\section{Materials}

Low density polyethylene (LDPE) used under this investigation was obtained from IPCL (India). Mica practical (P) and commercial (C) grades, silica, soya protein isolate (SPI), potassium permanganate $\left(\mathrm{KMnO}_{4}\right)$, and alumina $\left(\mathrm{Al}_{2} \mathrm{O}_{3}\right)$ were obtained from Ranbaxy Laboratories Ltd. (India). All the fillers had an average particle size of about $15 \mu \mathrm{m}$.

\section{Compounding and film blowing of LDPE films}

LDPE was compounded with the fillers mentioned, using Haake twin screw CTW 100 extruder (Germany) with L/D ratio 33/1. A temperature profile of $156-$ $180^{\circ} \mathrm{C}$ was maintained during the process. The compounded LDPE was then blown into films of thickness 
TABLE I

Physicomechanical and Optical Properties of LDPE and Filled LDPE Films

\begin{tabular}{|c|c|c|c|c|c|c|}
\hline Sample & $\begin{array}{c}\text { Tensile } \\
\text { strength } \\
(\mathrm{MPa})\end{array}$ & $\begin{array}{c}\text { Elongation } \\
\text { at break } \\
(\%)\end{array}$ & $\begin{array}{c}\text { Tear } \\
\text { strength } \\
(\mathrm{kg})\end{array}$ & $\begin{array}{c}\text { Burst } \\
\text { strength } \\
(\mathrm{MPa})\end{array}$ & $\begin{array}{c}\text { Transmittance } \\
(\%)\end{array}$ & Haze $(\%)$ \\
\hline LDPE & 12.42 & 187 & 0.13 & 0.04 & 76.8 & 18.5 \\
\hline LDPE + $0.75 \%$ Silica & 12.46 & 266 & 0.16 & 0.06 & 68.9 & 22.1 \\
\hline LDPE + $1 \%$ Silica & 16.87 & 280 & 0.16 & 0.06 & 67.2 & 20.0 \\
\hline LDPE + 1\% Mica $(\mathrm{P})$ & 10.00 & 226 & 0.13 & 0.06 & 68.2 & 17.6 \\
\hline LDPE + 1\% Mica (C) & 10.40 & 214 & 0.13 & 0.05 & 71.7 & 16.2 \\
\hline LDPE + $2 \%$ Mica $(\mathrm{P})$ & 15.11 & 217 & 0.19 & 0.08 & 67.2 & 22.2 \\
\hline $\mathrm{LDPE}+2 \% \mathrm{Mica}(\mathrm{C})$ & 17.95 & 238 & 0.14 & 0.06 & 68.6 & 23.6 \\
\hline LDPE + $3 \%$ Mica (P) & 14.13 & 208 & 0.21 & 0.08 & 53.0 & 46.5 \\
\hline LDPE + 3\% Mica (C) & 16.87 & 210 & 0.14 & 0.06 & 53.5 & 51.3 \\
\hline LDPE + $1 \%$ SPI & 16.19 & 219 & 0.09 & 0.10 & 64.2 & 18.8 \\
\hline $\mathrm{LDPE}+2 \% \mathrm{KMnO}_{4}$ & 12.26 & 300 & 0.13 & 0.14 & 88.5 & 38.2 \\
\hline $\mathrm{LDPE}+1 \% \mathrm{Al}_{2} \mathrm{O}_{3}$ & 8.34 & 298 & 0.12 & 0.17 & 90.2 & 24.2 \\
\hline
\end{tabular}

$75 \mu \mathrm{m}$, using KONARK single screw extruder (India) with $\mathrm{L} / \mathrm{D}$ ratio $22 / 1$. Film blowing was carried out maintaining a temperature profile $170-190^{\circ} \mathrm{C}$.

\section{Techniques}

The filled LDPE films have been tested for tensile strength and percentage elongation at break, using INSTRON 4302 (USA) Universal Testing Machine (UTM) as per ASTM D-882. Elemendorf tear strength has been determined according to ASTM D-1922. Minimum of five samples were tested at room temperature for each composition and the average values have been reported. The optical properties like percent transmission of light and haze were measured as per ASTM D-1003, using Suga test hazemeter (Model 206, Japan). The water vapor transmission rate (WVTR) and oxygen transmission rate (OTR) were measured as per ASTM D 96 and ASTM D 1434-66, respectively.

\section{X-ray recording and profile analysis}

X-ray diffraction data on LDPE and filled LDPE films were collected on a STOE X-ray powder diffractom- eter with germanium monochromated radiation of $\mathrm{Cu}$ $\mathrm{K}_{\alpha}(\lambda=1.5418 \AA)$ in a transmission mode, using a curved position sensitive detector in the $2 \theta$ range from $5^{\circ}$ to $30^{\circ}$, at a scan rate of $4^{\circ} / \mathrm{min}$. The intensity was corrected for Lorentz polarization factors and also for instrumental broadening, using Stokes deconvolution method. ${ }^{20}$

We have estimated crystal imperfection parameters such as crystal size $(\langle N\rangle)$ and lattice strain $(g$ in \%) by simulating the profile described earlier ${ }^{21-24}$ and using Bragg reflection at $2 \theta \approx 21^{\circ}$ and $23^{\circ}$. Here $\langle N\rangle$ represents the average number of unit cells counted in a direction normal to the Bragg planes and at the end of that number of unit cells, one finds a deviation of lattice constant by $g \%$.

Simulation of intensity profile was carried out on the basis of Hosemann's one-dimensional linear paracrystalline model and the equations used for this purpose are given below. ${ }^{34}$

The scattered intensity is

$$
I(s)=I_{N-I}(s)+I_{N}^{\prime}(s)
$$

where

TABLE II

Barrier Properties of LDPE and Filled LDPE Films

\begin{tabular}{lcc}
\hline \multicolumn{1}{c}{ Sample } & $\begin{array}{r}\text { WVTR }\left(\mathrm{g} / \mathrm{m}^{2} / 24 \mathrm{~h} \text { at }\right. \\
\left.38^{\circ} \mathrm{C} / 90 \mathrm{RH}\right)\end{array}$ & $\begin{array}{c}\mathrm{OTR}\left(\mathrm{g} / \mathrm{m}^{2} / 24 \mathrm{~h} \text { at }\right. \\
\left.38^{\circ} \mathrm{C} / 90 \mathrm{RH}\right)\end{array}$ \\
\hline $\mathrm{LDPE}$ & 8.1 & 7560 \\
$\mathrm{LDPE}+0.75 \%$ Silica & 6.8 & 7654 \\
$\mathrm{LDPE}+1 \%$ Silica & 7.2 & 7840 \\
$\mathrm{LDPE}+1 \%$ Mica (P) & - & - \\
$\mathrm{LDPE}+1 \%$ Mica (C) & 7.1 & 7581 \\
$\mathrm{LDPE}+2 \%$ Mica (P) & 7.2 & 7120 \\
$\mathrm{LDPE}+2 \% \mathrm{Mica}(\mathrm{C})$ & 7.4 & 7653 \\
$\mathrm{LDPE}+3 \% \mathrm{Mica}(\mathrm{P})$ & 7.8 & 7850 \\
$\mathrm{LDPE}+3 \% \mathrm{Mica}(\mathrm{C})$ & 7.9 & 7640 \\
$\mathrm{LDPE}+1 \% \mathrm{SPI}_{\mathrm{LDPE}}+2 \% \mathrm{KMnO}_{4}$ & 7.4 & 7830 \\
$\mathrm{LDPE}+2 \% \mathrm{Al}_{2} \mathrm{O}_{3}$ & 6.7 & 7682 \\
\hline
\end{tabular}



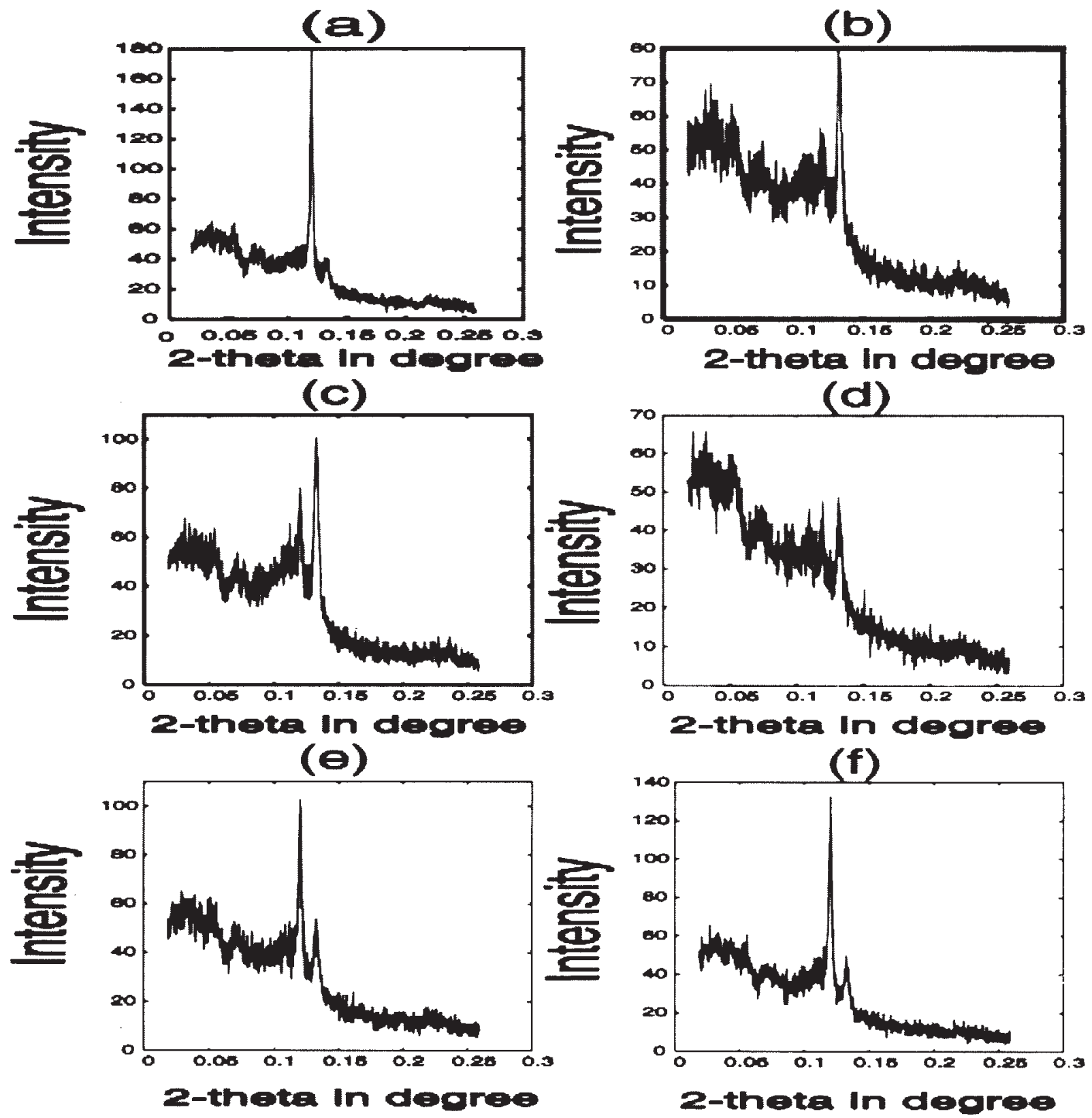

Figure 1 Wide angle X-ray diffractograms of LDPE films. (a) LDPE (unfilled), (b) LDPE + 0.75\% Silica, (c) LDPE + 1\% Silica, (d) LDPE + 1\% Mica (P), (e) LDPE + 1\% Mica (C), (f) LDPE + 2\% Mica (P), (g) LDPE + 2\% Mica (C), (h) LDPE + 3\% Mica (P), (i) LDPE + 3\% Mica (C), (j) LDPE + 1\% SPI, (k) LDPE + 2\% $\mathrm{KMnO}_{4}$.

$$
\begin{aligned}
I_{N}^{\prime}(s)=2 \operatorname{Re}\left[\left(1-I^{N+1}\right) /(1-I)+\right. & \left\{I \nu / d(1-I)^{2}\right\}\left\{I^{N}[N(1\right. \\
& -I)+1]-1\}]^{-1}
\end{aligned}
$$

with $\nu=2 i a^{2} s+d, I=I_{1}(s)=\exp \left(-a^{2} s^{2}+i d s\right)$, and $a^{2}$ $=\omega^{2} / 2$.

$I_{N}^{1}(s)$, the modified intensity for the probability peak centered at $D$ is given by,

$$
\begin{aligned}
I_{N}^{1}(s)=\frac{\left(2 a_{N}\right)}{D(\pi)^{1 / 2}} \exp (i D s)[1 & -a_{N} s\left\{2 D\left(a_{N} s\right)\right. \\
& \left.\left.\left.+i(\pi)^{1 / 2}\right\} \exp \left(-a_{N}^{2} S^{2}\right)\right\}\right]
\end{aligned}
$$

where $a_{N}^{2}=N \omega^{2} / 2, \omega$ is the standard deviation of the nearest neighbor probability function ${ }^{24-26}$ and $D\left(a_{N} s\right)$ is the Dawson's integral or the error function with purely complex argument and can be computed. $\langle N\rangle$ is the number of unit cell counted in a direction perpendicular to the $(h k l)$ Bragg plane, $g$ is the lattice strain given by $\Delta d / d(=\omega / d), d$ is the spacing of the $(h k l)$ planes, 'Re' refers to the real part of the expression, $a$ is related to the standard deviation, $\omega$ of the lattice distribution function. The experimental profile between $\mathbf{s}_{0}$ and $\mathbf{s}_{0}+\mathbf{s}_{0} / 2$ (or $\mathbf{s}_{0}$ and $\mathbf{s}_{0}+B / 2 \mathrm{~d}$, if there is truncation of the profile $B<1$ and $B=1$, when there 

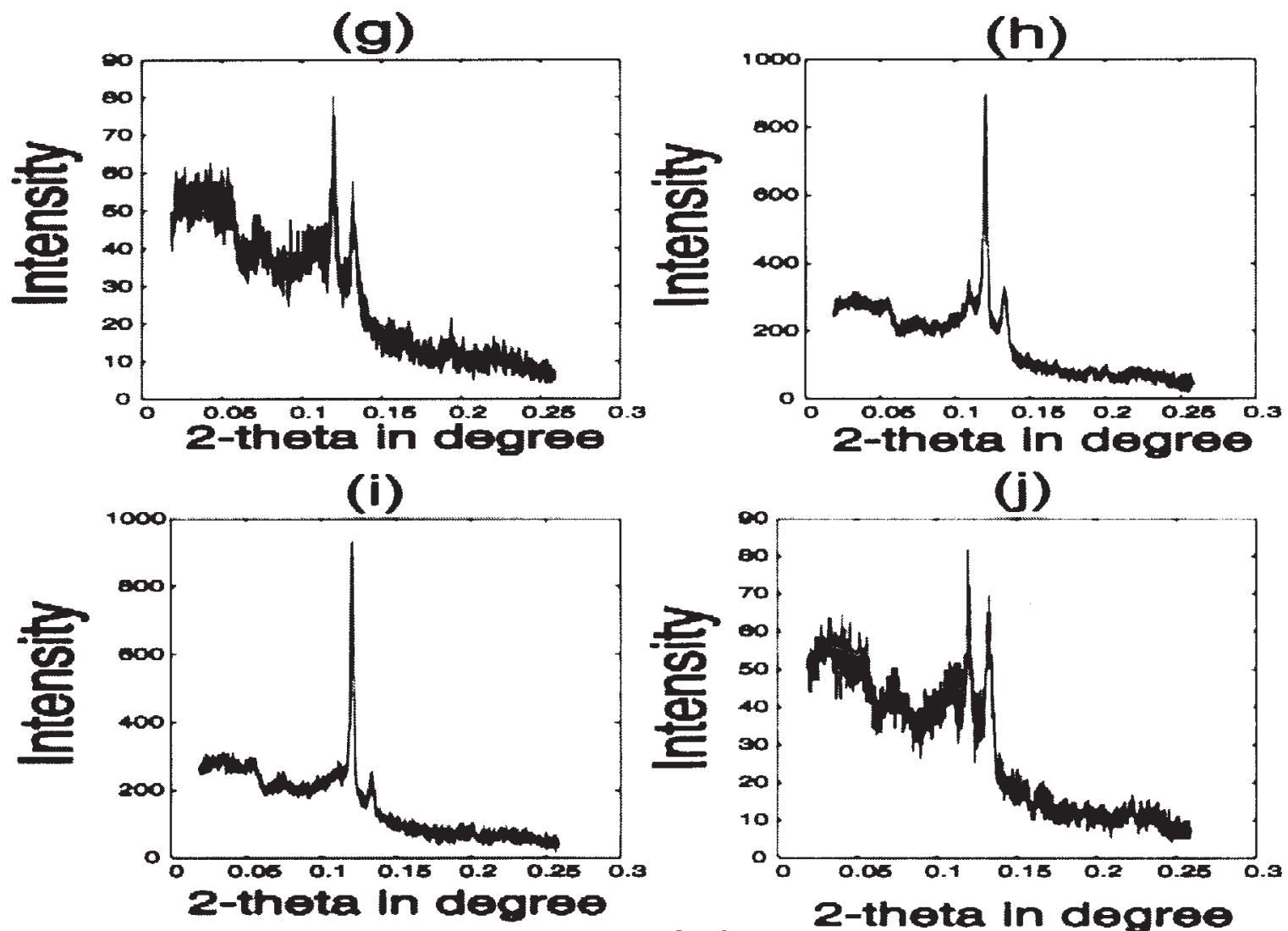

(k)

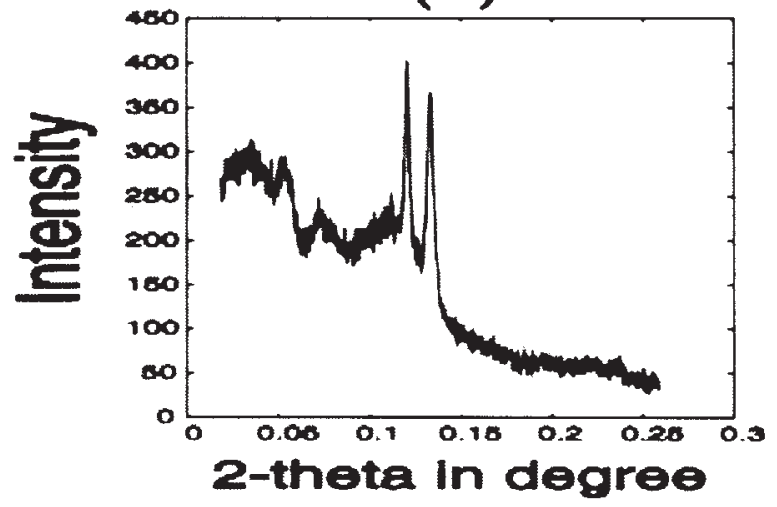

Figure 1 (Continued from the previous page)

is no truncation, $d=d_{h k l}$ ) is matched with corresponding simulated order of reflection between the calculated and experimental normalized intensity values. SIMPLEX, a multidimensional algorithm ${ }^{26}$ is used for minimization. This method gives the best values of $\langle N\rangle$ and $g$.

Using this procedure, the values of the crystal size $(\langle N\rangle)$ and lattice strain $(g)$ are obtained for X-ray reflections at $2 \theta \approx 21^{\circ}$ and $23^{\circ}$. Here $d_{h k l}$ is the perpendicular distance from the origin to the $(h k l)$ plane, $\omega$ is the standard deviation of the probability distribution associated with the distortion of the lattice and it is related to the strain by $g^{2}=(\omega / d)^{2}$. Here, $s$ is $(\sin \theta) / \lambda$ and $\mathbf{s}_{0}$ is the scattering vector corresponding to the peak of the X-ray profile. Here, the surface-weighted $\left(D_{s}\right)$ crystal size is given by $D_{s}=\langle N\rangle d_{h k l}$.

\section{RESULTS AND DISCUSSION}

Physicomechanical properties

The physicomechanical properties of all the filled LDPE films have been presented in Table I. Some of these data have been published elsewhere. ${ }^{19}$ It is clearly evident from the table that, with the incorporation of fillers, the tensile strength of the film has decreased in accordance with the reported observations. ${ }^{10,17,27}$ Also, with the increase in the filler content 
TABLE III

Microcrystalline Parameters of Filled LDPE Films

\begin{tabular}{|c|c|c|c|c|c|c|c|}
\hline Sample & $2 \theta$ & $\langle N\rangle$ & $g(\%)$ & $D(\%)$ & $\alpha^{*}$ & $d_{h k l}(\AA)$ & $D_{1}(\AA)$ \\
\hline \multirow[t]{2}{*}{ LDPE } & 20.30 & 19.30 & 2.30 & 0.90 & & 4.37 & 84.34 \\
\hline & 23.80 & 32.50 & 6.50 & 1.50 & 0.2 & 3.73 & 121.23 \\
\hline \multirow[t]{2}{*}{ LDPE + $0.75 \%$ Silica } & 21.58 & 21.50 & 1.20 & 2.60 & & 4.11 & 84.44 \\
\hline & 22.90 & 16.80 & 4.30 & 1.40 & 0.1 & 3.88 & 65.17 \\
\hline \multirow[t]{2}{*}{ LDPE $+1 \%$ Silica } & 21.97 & 20.30 & 1.40 & 2.90 & & 4.15 & 84.25 \\
\hline & 23.70 & 14.50 & 4.20 & 1.20 & 0.1 & 3.75 & 54.38 \\
\hline \multirow[t]{2}{*}{ LDPE $+1 \%$ Mica $(P)$} & 21.30 & - & - & - & - & 4.17 & - \\
\hline & 23.30 & 18.20 & 12.10 & 1.10 & - & 3.81 & 69.41 \\
\hline \multirow[t]{2}{*}{$\mathrm{LDPE}+1 \%$ Mica $(\mathrm{C})$} & 21.30 & - & - & - & - & 4.17 & - \\
\hline & 23.34 & 18.20 & 12.10 & 1.10 & - & 3.81 & 69.41 \\
\hline \multirow[t]{2}{*}{ LDPE + $2 \%$ Mica (P) } & 21.40 & 13.40 & 6.40 & 1.59 & & 4.15 & 55.28 \\
\hline & 23.30 & 13.70 & 6.20 & 1.78 & 0.2 & 3.81 & 52.25 \\
\hline \multirow[t]{2}{*}{ LDPE + $2 \%$ Mica (C) } & 21.30 & 15.60 & 3.40 & 1.20 & & 4.17 & 65.05 \\
\hline & 23.50 & 14.50 & 3.50 & 1.80 & 0.2 & 3.78 & 54.81 \\
\hline \multirow[t]{2}{*}{ LDPE + 3\% Mica $(P)$} & 21.40 & 20.30 & 2.30 & 0.76 & & 4.15 & 84.20 \\
\hline & 23.50 & 11.30 & 8.40 & 0.66 & 0.2 & 3.78 & 42.73 \\
\hline \multirow[t]{2}{*}{$\mathrm{LDPE}+3 \%$ Mica $(\mathrm{C})$} & 21.30 & 18.60 & 1.10 & 0.66 & & 4.17 & 77.51 \\
\hline & 23.50 & 15.70 & 2.90 & 1.01 & 0.2 & 3.78 & 59.37 \\
\hline \multirow[t]{2}{*}{$\mathrm{LDPE}+1 \% \mathrm{SPI}$} & 21.28 & 22.70 & 5.20 & 2.70 & & 4.17 & 94.66 \\
\hline & 23.61 & 14.60 & 4.40 & 2.00 & 0.2 & 3.76 & 54.90 \\
\hline \multirow[t]{2}{*}{$\mathrm{LDPE}+2 \% \mathrm{KMnO}_{4}$} & 21.37 & 20.30 & 2.20 & 1.80 & & 4.15 & 84.25 \\
\hline & 23.69 & 16.30 & 3.40 & 0.90 & 0.1 & 3.75 & 61.13 \\
\hline \multirow{2}{*}{$\mathrm{LDPE}+2 \% \mathrm{Al}_{2} \mathrm{O}_{3}$} & 22.50 & 13.80 & 6.80 & 1.72 & & 3.95 & 54.47 \\
\hline & 24.10 & 14.10 & 6.40 & 1.73 & 0.3 & 3.69 & 52.01 \\
\hline
\end{tabular}

in cases of silica and mica, an increase in tensile strength is observed. This is because of the reinforcing effect induced by these fillers. ${ }^{17,28}$ However, at 3\% mica, a reduction in the tensile strength is observed, indicating $2 \%$ mica content as the optimum level in the LDPE film. The percentage elongation value for unfilled LDPE film is $187 \%$ and has increased to a maximum of $300 \%$ for $2 \% \mathrm{KMnO}_{4}$-filled LDPE film.

Tear strength is a significant property for high capacity pouches, bags, and other industrial applications. These values have increased with the addition of filler except for SPI. This is attributed to the fact that the fillers act as obstructions for tear propagation. ${ }^{29}$

\section{Optical properties}

The optical properties viz., percentage transmittance and haze of the filled LDPE films are reported in Table I. As expected, percentage transmittance of the LDPE films has decreased from 74.8 to $52 \%$ with the incorporation of the fillers. It is also observed that the haze value lies in the range of 18.5-52.3 for filled films. The increase in haze after incorporation of fillers is due to the scattering of light by particulate fillers. ${ }^{30-33}$

\section{Barrier properties}

In food packaging industries, permeability to water vapor and gases, particularly oxygen, critically decides the protective properties of the plastic films.
Varied permeabilities are also desired in certain applications like modified atmosphere packaging. Water vapor transmission rate (WVTR) and oxygen transmission rate values obtained in the present study are presented in Table II. It has been observed that WVTR has markedly changed in filled LDPE films. The WVTR lies in the range $6.7-7.9 \mathrm{~g} / \mathrm{m}^{2} / 24 \mathrm{~h}$ at $38^{\circ} \mathrm{C} /$ 90RH for filled LDPE films. The OTR for filled films vary by $\pm 8 \%$ from the value observed for unfilled film $\left(7560 \mathrm{~g} / \mathrm{m}^{2} / 24 \mathrm{~h}\right.$ at $\left.38^{\circ} \mathrm{C} / 90 \mathrm{RH}\right)$.

\section{Wide angle $X$-ray scattering analysis}

Wide angle $X$-ray diffractograms for pure and filled LDPE films are given in Figures 1(a)-1(k). Wide angle $X$-ray scattering patterns of these films show that there are two sharp reflections at (110) and (200) corresponding to the Bragg angle $2 \theta \approx 21.8$ and $24^{\circ}$, respectively. The micro structural parameters such as crystal size $\langle N\rangle$, lattice strain $(g)$, and enthalpy $\left(\alpha^{*}\right)$ are determined by matching the simulated intensity profile, using eqs. (1)-(3) with the experimental data for all the samples studied here and the obtained results are tabulated in Table III. For the sake of completeness, we have reproduced in Figure 2 the simulated and experimental intensity profiles for some of the filled LDPE films.

From Table III, the following results emerge. They are: 

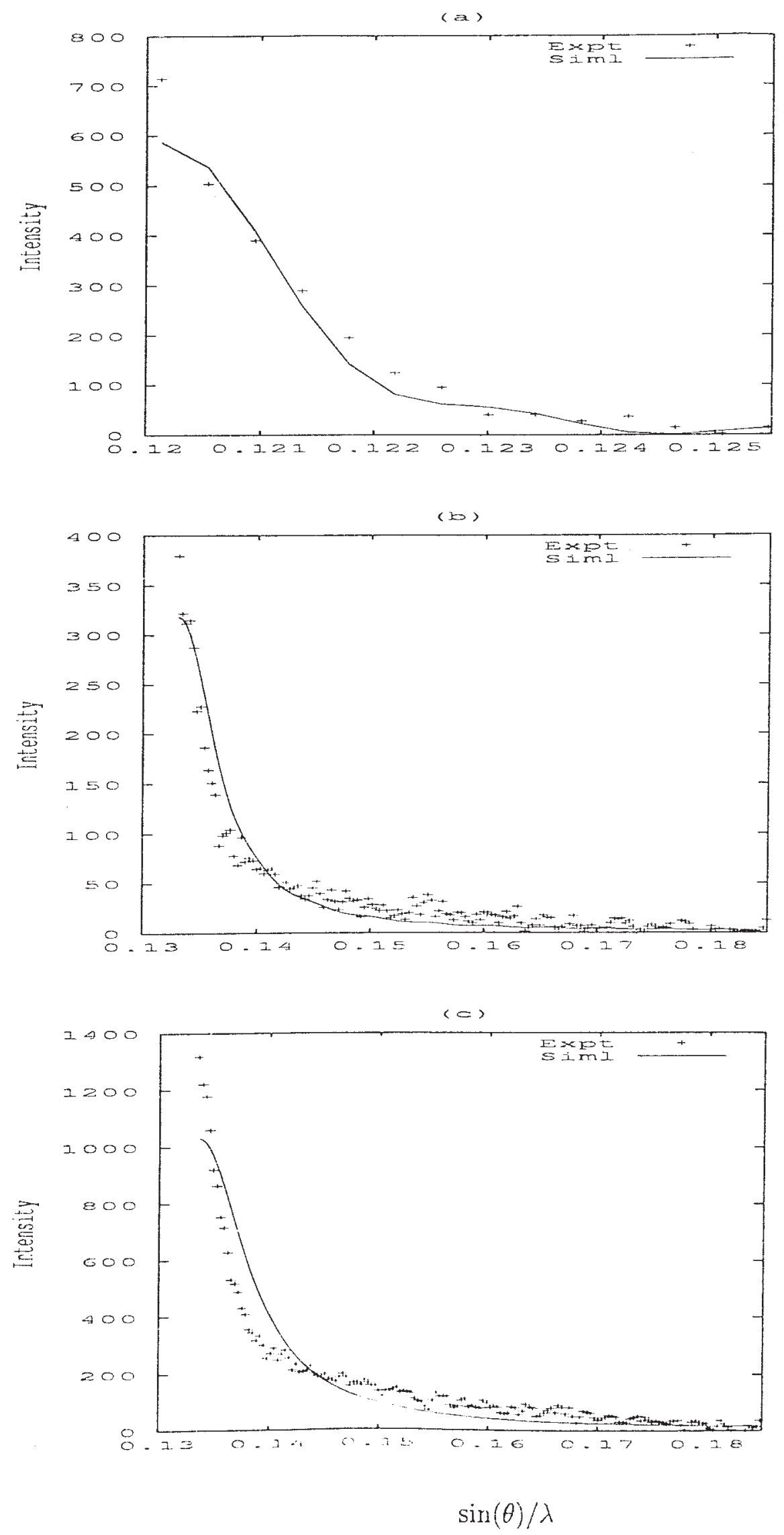

Figure 2 Experimental and simulated intensity profiles of (a) LDPE (unfilled), (b) LDPE 1\% Silica, and (c) LDPE + 2\% $\mathrm{KMnO}_{4}$. 

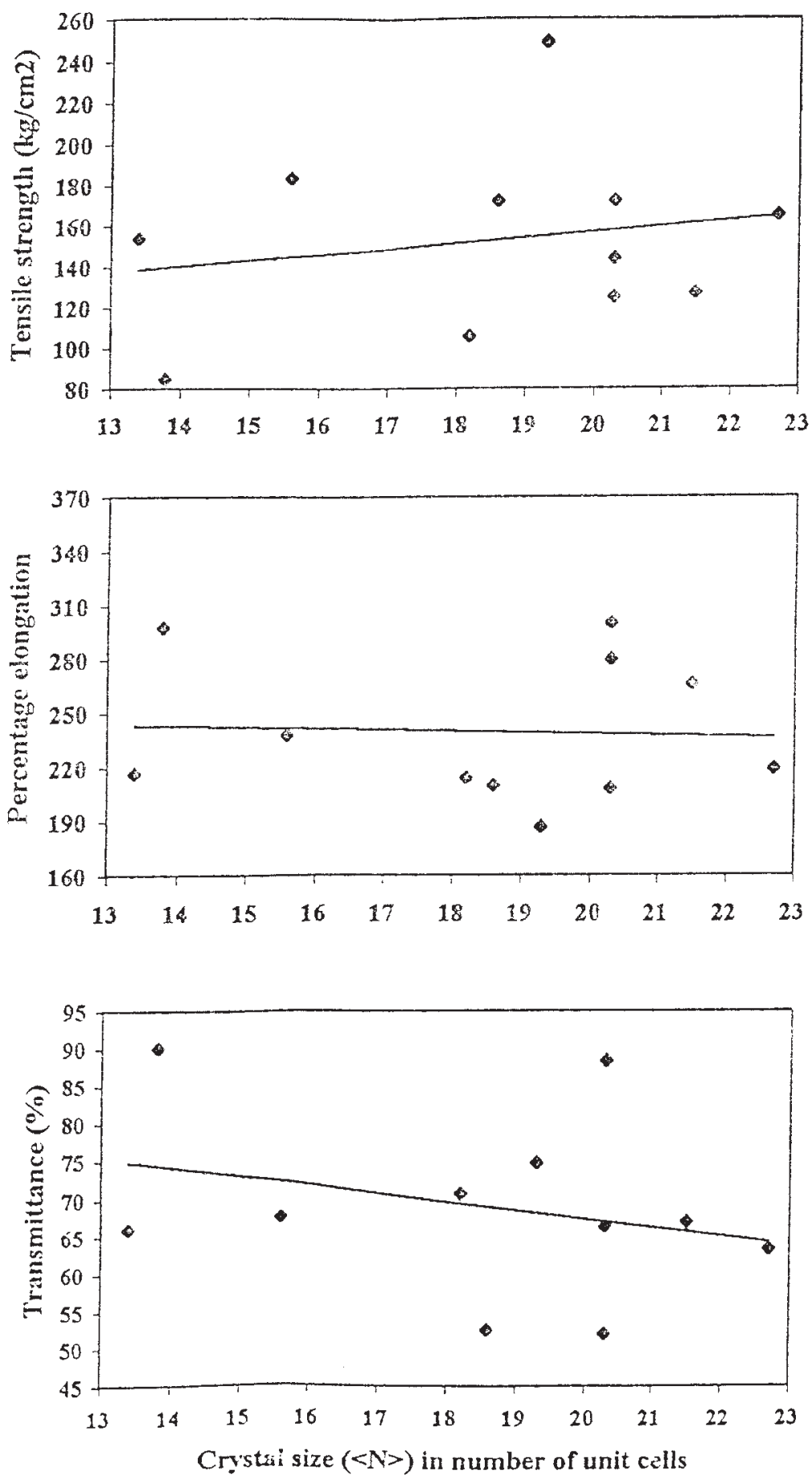

Figure 3 Variation of (a) tensile strength (b) percent elongation, and (c) percent transmission with crystal size for different fillers in LDPE films.

1. Reduction of crystal size with the incorporation of fillers has been observed. This indicated that the addition of fillers increases the disorderliness in the polymer network of LDPE. This is due to the weakening of van der Waal's forces between the polymer molecules.

2. This decrease in crystal size is in consonance with the observed physical property like ten- sile strength that has also decreased. The extent of reduction in tensile strength is varying and we observe from the results that it is more in $\mathrm{LDPE}+1 \% \mathrm{Al}_{2} \mathrm{O}_{3}$ and less in LDPE $+2 \%$ mica (C) films. The variation of tensile strength with crystal size in filled LDPE films is shown in Figure 3 . The tensile strength shows a slight increase for LDPE $+2 \%$ mica $(\mathrm{C})$, which may 

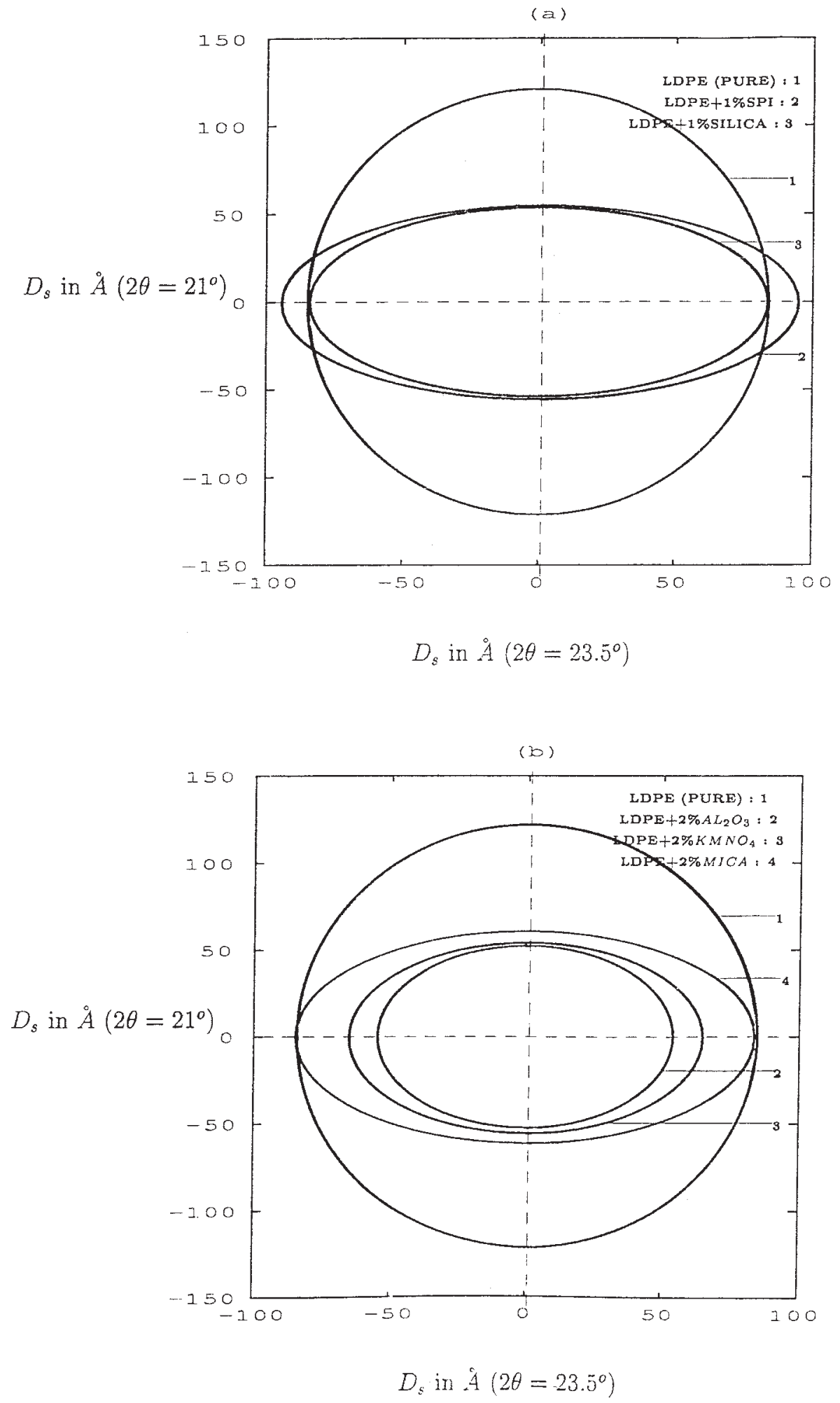

Figure 4 Shape ellipsoid of crystallites of unfilled and filled LDPE films.

not be directly related to increase in crystalline region.

3. Contrary to the above results, we observe that the percentage of elongation at break increases with fillers studied when compared with pure LDPE.
The reason for such a behavior lies in the fact that the fillers act as interfacial adhesives between two polymer layers. Infact, such observations have been reported in LDPE films blended with chromic acid. ${ }^{1}$ This particular physical property 
is independent of the variation of crystal size and lattice strain values of LDPE films.

4. Barrier property changes with fillers in LDPE. This is again attributed to the variation of crystal size with the adding of fillers.

5. A graphical plot of crystalline-shaped ellipsoid was obtained by taking one of the crystal size values corresponding to (200) along $X$-axis and the other parameter corresponding to (110) along $Y$-axis for pure and filled LDPE films and it is shown in Figures 4(a)-4(b). From this, it is evident that there are significant changes in the crystalline-shaped ellipsoids depending on the nature of fillers. The region of crystalline order of pure LDPE film decreases with the incorporation of fillers, which essentially implies increase in amorphous region.

From the parameters like crystal size and lattice strain, we can estimate the minimum enthalpy that defines the equilibrium state of micro paracrystals in filled LDPE films using the relation $\alpha^{*}=\langle N\rangle^{1 / 2} g{ }^{34}$ This $\alpha^{*}$ value implies physically that the growth of paracrystals in a particular material is appreciably controlled by the level ' $g$ ' in the net plane structure. The estimated values of enthalpy are also given in Table III The value of $\alpha^{*}$ for unfilled and filled LDPE films lie in the range of 0.1-0.3, which is in confirmation with the observation of polymers by Hosemann. This indicates that the amount of energy needed for the formation of polymer network has changed with fillers.

The reason for such changes can be attributed to indiscriminate filler granules in the matrix of LDPE, which generally tends to lower the short range interaction between the layers of LDPE, leading to increase in disorder in the lattice. These changes result in more broadening of X-ray Bragg reflections and hence, decrease in microstructural parameters. On a macroscopic scale, these affect the physical parameters like tensile strength, percentage of elongation, and percentage of transmittance.

\section{CONCLUSIONS}

We observe that there are changes, both microscopically and macroscopically, in LDPE films when fillers are incorporated. These are quantified in terms of micro crystalline parameters and also physical parameters like tensile strength, percentage elongation, etc.
We have also examined the reasons for such changes in terms of weakening of intermolecular van der Waal's forces.

\section{References}

1. Kong, J.-S.; Lee, D.-J.; Kim, H.-D. J Appl Polym Sci 2001, 82, 677.

2. Huang, M.-R.; Li, S.-X.; Dong, Z.-Q.; Feng, W.; Wang, X.-Y.; Gu, S.-Y.; Wu, Y.-H.; Huang, X.-A. J Appl Polym Sci 2002, 83, 3013.

3. Lin, Y. J Appl Polym Sci 1997, 63, 811.

4. Lei, J. J Appl Polym Sci 2001, 81, 2881.

5. Bandophadyay, D.; Panda, A. B.; Pramanik, P. J Appl Polym Sci 2001, 82, 406.

6. Bag, D. S.; Pradeep Kumar, V.; Maiti, S. J Appl Polym Sci 1991, 71,1041 .

7. Lu, J.; Sue, H.-J. J Polym Sci Part B: Polym Phys 2002, 40, 507.

8. Rana, A. K.; Mandal, A.; Banerjee, A. N. J Appl Polym Sci 2000, 76,684 .

9. Figg, K. Packag Technol Sci 1989, 2, 215.

10. Gennadoise, A.; Weller, C. L.; Tesin, R. F. Cereal Chem 1993, 70, 426.

11. Kemper, E. L.; Bahl, K. S. J Plast Film Sheet 1994, 10, 336.

12. Robert, B. S. U.S. Pat. 4,336,301 (1982).

13. Vick, C. S.; Fairhurst, D. Plast Compos 1984, 7, 2.

14. Seymour, R. B.; Carraher, C. E. Structure Property Relation in Polymers; Plenum: New York, 1984.

15. Gordienko, V. P. Kompoz Polim Mater 1985, 27, 58.

16. Skripachav, V. I.; Kuznetsov, V. I.; Ivanchev, S. S. Plast Mater $1985,3,16$

17. Radosta, J. A. J Plast Film Sheet 1991, 7, 18.

18. Schumpt, H. P.; Bilogan, W. Kunststoffe 1993, 73, 6.

19. Siddaramaiah; Nagarahalli, R. T.; Ramakrishna, A.; Varadarajulu, A. J Plast Film Sheet 1997, 13, 252.

20. Stokes, A. R. Proc Phys Soc London 1948, 61, 382.

21. Press, W. H.; Flannery, B. P.; Teukolsky, S. A.; Vetterling, W. T. Numerical Recipes in C; Cambridge University Press: Cambridge, 1988. p 284.

22. Somashekar, R.; Hall, I. H.; Carr, P. D. J Appl Crystallogr 1989, $22,363$.

23. Hall, I. H.; Somashekar, R. J Appl Crystallogr 1991, 24, 1051.

24. Silver, M. M.Sc. Thesis, UMIST, UK, 1988.

25. Wilson, A. J. C. Elements of X-ray Crystallography; AddisonWesley: Reading, MA, 1970. p 191.

26. Press, W. H.; Flannery, B. P; Teukolsky, S. A.; Vetterling, W. T., Eds. Numerical Recipes; Cambridge University Press: Cambridge, UK, 1986; p 83.

27. Balzar, D. J Res Natl Inst Stand Technol 1993, 88, 32.

28. Chacko, V. P.; Farris, R. J.; Karasz, F. E. J Appl Polym Sci 1983, $28,2701$.

29. Rodster, J. A.; Riley, W. D. J Plast Film Sheet 1981, 7, 247.

30. Puffr, R.; Sebendra, J. J Polym Sci Part C: Polym Symp 1967, 16, 79.

31. Wang, G. C.; Wang, J. X.; Zhangs, Z. P. Polym Int 1991, 25, 237.

32. Siddaramaiah; Mallu, P.; Somashekhar, R. J Appl Polym Sci 1998, 68, 1739.

33. Khanna, Y. P.; Day, E. D.; Tsai, M. L.; Vaidyanathan, G. J Plast Film Sheet 1997, 13, 197

34. Hosemann, R. Colloid Polym Sci 1982, 268, 982. 